\title{
SOME REFLECTIONS ON ACTINIAN BEHAVIOR
}

$\operatorname{AUTHOR}(S)$ :

Ross, Donald M.

\section{CITATION:}

Ross, Donald M.. SOME REFLECTIONS ON ACTINIAN BEHAVIOR.

PUBLICATIONS OF THE SETO MARINE BIOLOGICAL LABORATORY 1973, 20: 501-512

ISSUE DATE:

1973-12-19

URL:

http://hdl.handle.net/2433/175762

RIGHT: 


\title{
SOME REFLECTIONS ON ACTINIAN BEHAVIOR
}

\author{
DONALD M. ROSS \\ Zoology Department, University of Alberta, Edmonton, Canada
}

With 4 Text-figures

Contents

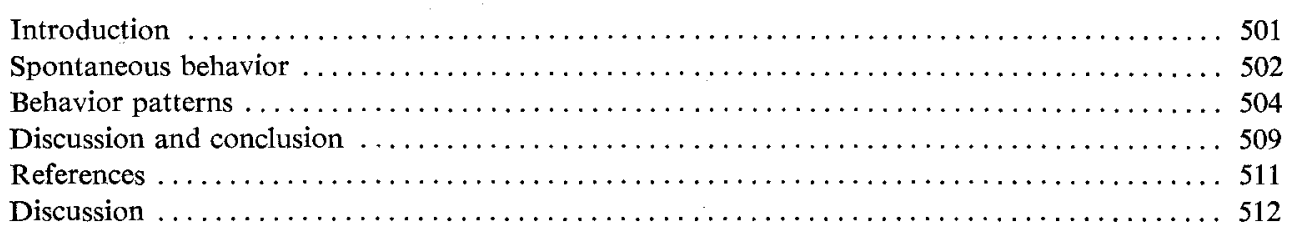

\section{Introduction}

Amongst the Cnidaria, behavioral studies, like morphological studies, have followed separate medusoid and polypoid tracks. One might expect sessile polyps to be unpromising subjects for behavioral work compared with medusae, whose activities are so much more visible. Moreover, medusae, unlike polyps, possess nervous systems with ganglia and nerves conveniently accessible for surgical and recording techniques. Indeed, MACKIE at the Salamanca meeting proposed that each ganglion of Sarsia should be regarded as a central nervous system, a sharp contrast with the complete absence of such aggregations in the polyps (MACKIE, 1971).

It can be a disadvantage, however, to study behavior against a background of visible rhythmic activity as occurs in medusae. It is this circumstance that makes polyps, and especially anemones which are mostly large, solitary creatures, surprisingly good for behavior studies. I shall review here some activities of anemones in order to advance some suggestions about the type and level of neuromuscular organisation that carries out these activities. I shall remind you of some of the phenomena shown in our film "Passengers or Partners?" and I shall comment on some other observations and some earlier work.

The general impression of anemones as permanently sessile is only partially true. There are numerous anemones that do not have adhesive pedal discs, such as the large tribe Athenaria of CARLgREN (1949) which includes the genera Edwardsia and Peachia. These and others engage in various burrowing and locomotory activities which are more worm-like than polypoid. If we add to these the anemones that swim, creep about, or climb on shells in preference to other surfaces, and if we recall those 
that have specific interactions with other invertebrates, the notion arises that perhaps only a minority of actinians live the permanently-attached sessile lives generally thought to be typical of the group. I intend to review these atypical activities, describing first some spontaneous activities and then dealing with some special behavior patterns.

\section{Spontaneous Behavior}

One sees many examples of spontaneous behavior in actinians. I refer here to the generally slow changes in shape, volume and posture. These are cycles in which expansion, elongation, retraction, contraction, water expulsion and collapse occur as first described by BATHAM and PANTIN (1950). We think of these as spontaneous movements insofar as they cannot be related to specific stimuli, though they sometimes can be correlated with phases in a feeding-defecation cycle. But in general they are standard basic rhythms that go on in the absence of any detectable stimuli, e.g., light, food, vibration or pressure.

An example is seen in the Australasian anemone Phlyctenactis tuberculosa. It displays spontaneous activity of a particularly active kind. Figures 1 A and 1B show $P$. tuberculosa in the laboratory crawling on the seaweed on which it lives in nature almost perfectly camouflaged. The slow changes of shape that one sees in the laboratory are about ten times faster than the slow changes of shape seen in Metridium and Calliactis. The animal has a bizarre appearance, due in part to the vesicles which may be full and extended or empty and collapsed in appearance. The significance of this behavior in the life of the animal and the mechanism of its physiological control are quite unknown.

The spontaneous activities of anemones are initiated presumably by excitation in certain neurones which, for want of a better name, we call "pacemakers". Apparently these set in motion slow waves of conducted excitation. But the rate of conduction is exceedingly slow compared with any other activities based on excitation conducted through the nervous system. The passage of waves of contraction in Metridium, say $5 \mathrm{~cm}$ in length, may take 1 minute or more. This means that the excitatory wave is travelling at a rate of less than one millimeter per second. This rate of conduction would seem to be too slow for nerve and it is believed that excitation in these activities, once triggered, spreads directly from muscle cell to muscle cell. Graham HoyLE, well known for his work on the nerves and muscles of arthropods and other higher invertebrates, worked first of all on anemones and he has retained a continuing interest in their neuromuscular physiology. He described them once to me as "mystery bags", a term that reflects some of the frustration that one feels when one tries to produce a hypothesis that might explain how these spontaneous activities are initiated and controlled and built into the very life style of these animals. Their time course is much too slow to be attributed to MACKIE's epithelial excitation which is conducted at rates similar to conduction in the nerve net, i.e., minimum of $10 \mathrm{~cm}$ per sec. (MACKIE 


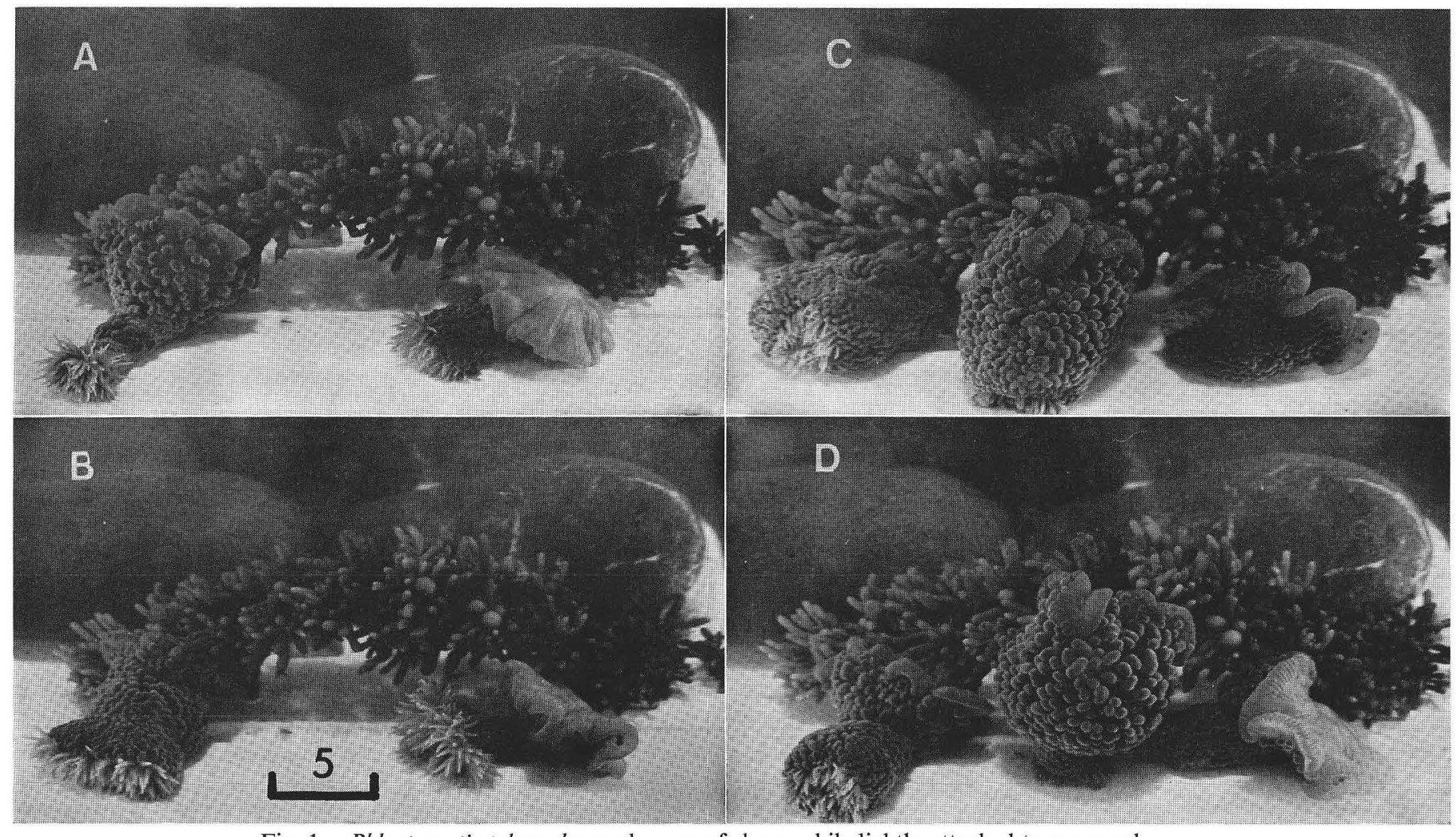

Fig. 1. Phlyctenactis tuberculosa; changes of shape while lightly attached to sea weed

(40 sec. between A \& B; 60 sec. between C \& D; Christchurch, New Zealand). Scale on Figs. 1, 2, 3 and 4 in cm. 
and PASSANO, 1968).

\section{Behavior Patterns}

Unlike the spontaneous activities so far considered, behavior patterns are sequences of activities that are directed toward definite goals. During the past twenty years, a whole new dimension has been added to our knowledge of actinian behavior patterns. When PARKer (1919) and later PANTIN (1952) discussed the activities of anemones as examples of primitive behavior, these activities consisted essentially of closing responses, feeding activities, various local responses to light and to chemical and tactile stimuli, along with those spontaneous activities described above. Several behavior patterns more recently discovered in actinians are specific, complex, discriminating and flexible. It is not necessary to describe these behavior patterns in much detail here since they have become very well known. They are: 1) responses to shells by anemones that are symbiotic with pagurids or molluses; 2) responses that lead to quick detachment and swimming; 3) relaxation and inhibition produced by weak mechanical stimulation.

\section{1) Responses to Shells}

The general sequence of neuromuscular events involved in the shell response has been described in our papers (Ross and SuTTON, 1961 and 1967) and demonstrated in several films. The response begins with tentacular contact and proceeds through slow detachment of the pedal disc and its resettlement on the shell. I have now studied this response in twelve different species, and the surprising fact that has emerged is that in almost every species the behavior pattern assumes a different character. Figures 2, 3 and 4 show five examples of behavior patterns of this kind that $\mathbf{I}$ have witnessed personally and found to be different in specific details.

a) Calliactis parasitica. This anemone transfers to shells by clinging strongly with its tentacles, detaching the pedal disc completely and somersaulting across the gap, then settling with a relatively flat pedal disk and a broadly expanded base (Fig. 2, $A$ and B).

b) Paranthus sociatus. This Japanese species is found only on two small molluscan hosts. Its transfer from other surfaces to these hosts or to shells has not been seen, but when already detached, it clings and settles displaying great mobility of the column. During settling the pedal disk is typically concave and adhesion begins at the edge of the base (Fig. 2, C and D).

c) Paracalliactis japonica. This large anemone has never been seen in the act of transferring itself to a shell but this is known to occur. In the laboratory, it has responded to shells and settled on them after preliminary stimulation by a hermit crab. The tentacles cling and the animal becomes exceptionally long and the column extremely mobile, flexing itself repeatedly more and more until the shell is reached. 
At the time of greatest flexion, the pedal disk sends out a blister towards the shell and, if contact is made, the pedal surface adheres and slowly spreads itself across the shell (Fig. 3, A and B).

d) Anemone "A". This small unidentified Japanese anemone commonly occurs with other larger anemones (e.g. Calliactis polypus) on pagurids. In numerous trials it has failed to transfer to a shell from other surfaces and it must be assumed that it lacks the capacity to make such transfers. When already detached, the tentacles cling very strongly to shells and the column becomes very short while the pedal disk is evaginated and becomes hemispherical. During the slight changes of position that ensue the edge of the swollen pedal disk usually makes contact with the shell and this provides the initial point of adhesion from which full settlement proceeds. Then the tentacles release themselves and the animal virtually rolls itself into an upright position (Fig. 3, C and D).
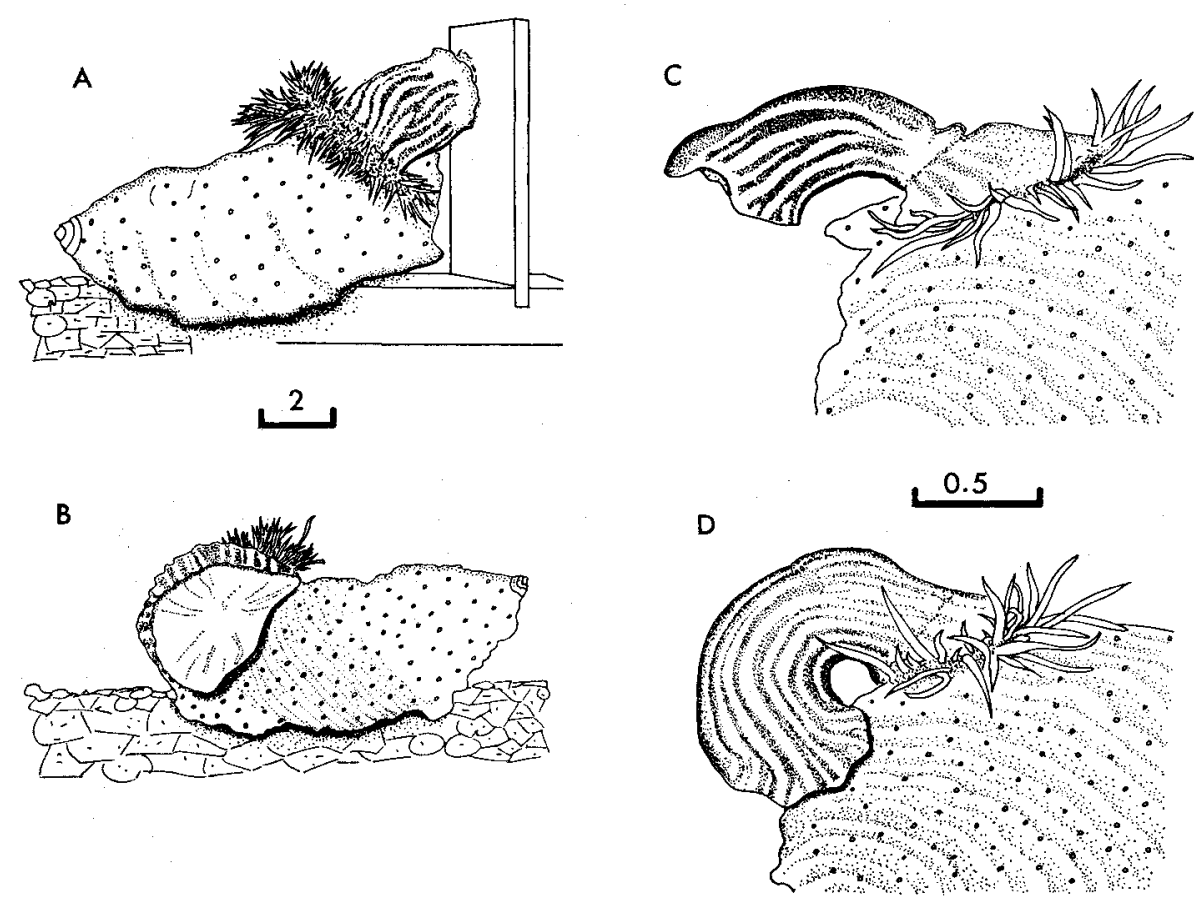

Fig. 2. A. Calliactis parasitica transferring from plastic plate to Buccinum shell; pedal disk completely free and column mobile.

B. C. parasitica settling on shell; adhesion beginning at edge of expanded but flattened pedal disk. ( 7 min. between A \& B; Plymouth, England).

C. Paranthus sociatus clinging to gastropod shell; pedal disk free and concave; column highly mobile.

D. $P$. sociatus settling on shell; pedal disk attaching at edge of concave surface; column in extreme flexion. ( $1 \mathrm{~min} .30 \mathrm{sec}$. between C \& D; Amakusa, Japan).

Figs. 2, 3 and 4 drawn from single frames on $16 \mathrm{~mm}$. films. 
e) Stomphia coccinea. This swimming sea anemone of the North Pacific and North Atlantic is frequently found living on mussels. It can transfer to mussel shells from other surfaces but, unlike $C$. parasitica, it does not detach completely. Instead, it lifts one edge of the foot and extends this to reach the shell, holding onto the original surface as a base until able to bridge the gap. During transfer and settlement, the column of Stomphia does not arch though it may be bent sharply at the oral and pedal ends. There is no general clinging of the tentacles although a few seem to act as anchors. The vast lateral expansion of the base and puffing of the pedal disk is evident just before contact with the shell is established (Fig. 4, A and B).

All these are slow behavior patterns associated with a fairly precise goal of settling on shells. Sometimes one sees portions of this behavior pattern when settling is taking place on other surfaces, especially if some other factors intervene such as stimu-
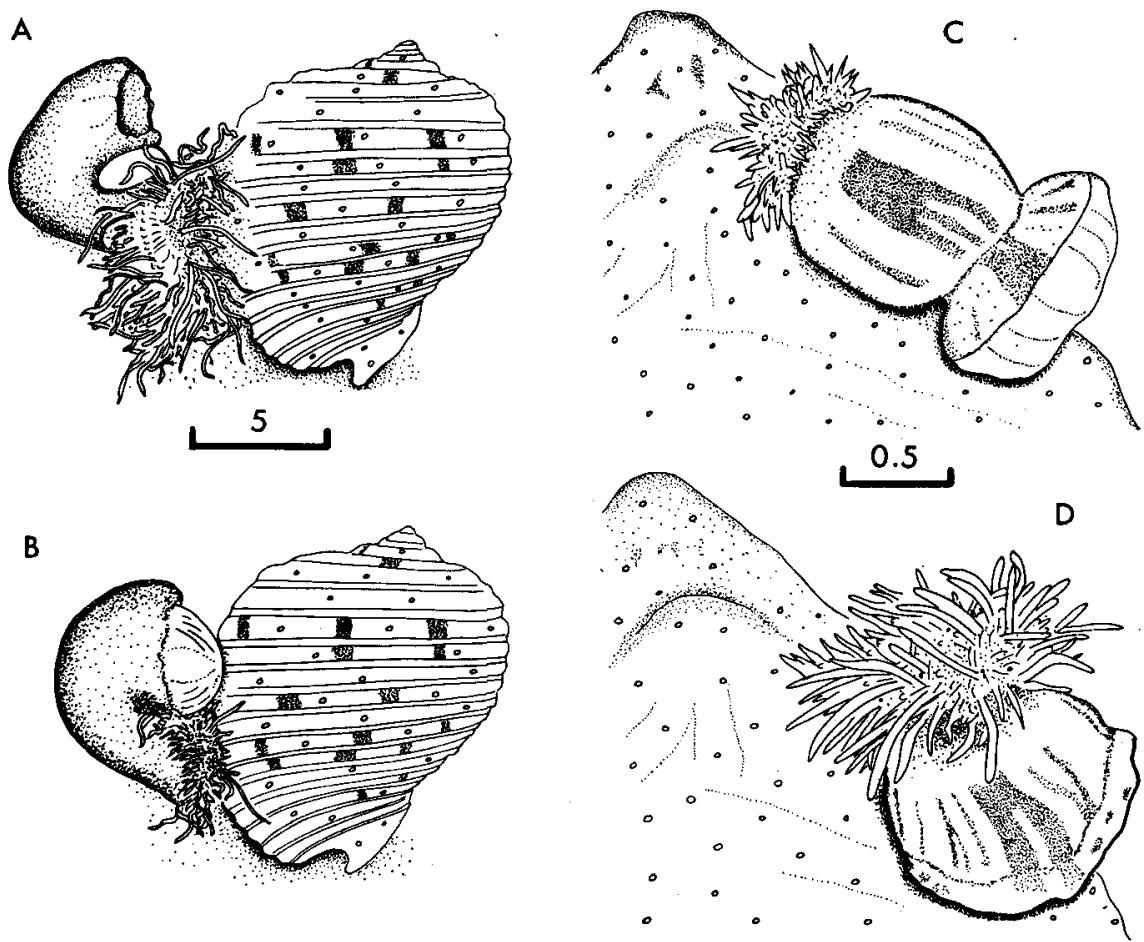

Fig. 3. A. Paracalliactis japonica clinging to shell; pedal disk concave and edge curled inwards; column in extreme flexion.

B. P. japonica settling on shell; pedal disk in shape of adhesive blister making contact with shell. (2.5 min. between A \& B; Misaki, Japan).

C. "Anemone A" clinging to large Charonia shell; tentacles withdrawn; pedal disk extremely convex and entire basal region swollen; column inflexible and constricted at base.

D. "Anemone A" settling on shell and reaching upright position; tentacles releasing hold; convex pedal disk flattening and adhering without flexion of column. ( 2 min. between $\mathrm{C}$ \& D; Shirahama, Japan). 
lation by a crab. But contact with the shell acts as a trigger for the whole program in all the cases that $I$ have seen.

It is not easy to see how the animals perform some of the movements that are carried out, e.g. the puffing of the foot that occurs in several of the cases described. The formation of a blister on the pedal disk or its evagination into a hemisphere can only be produced by a local relaxation of the disk accompanied by contraction of the column and the forcible occlusion of fluid in the pedal region. A description of some of these bizarre shapes in mechanical terms is difficult enough. A functional analysis of the role of the nervous system in coordinating such changes in shape in such specific circumstances is beyond one's capacity even to speculate upon at this time.

Yet the notion that there is a controlling system in the nerve net that guides activities of this kind is strongly supported now that MACFARLANE (1969) has identified such a system physiologically. He has been able to detect certain patterns of electrical activity in the ectoderm (his S.S.1 system) that coincide with the occurrence of the response to shells in Calliactis parasitica. Presumably such a system, once excited, can provide for an orderly sequence of events in any one of the cases here described.

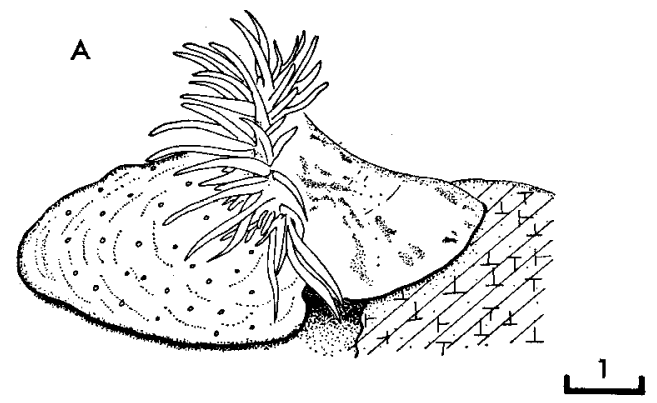

\section{B}

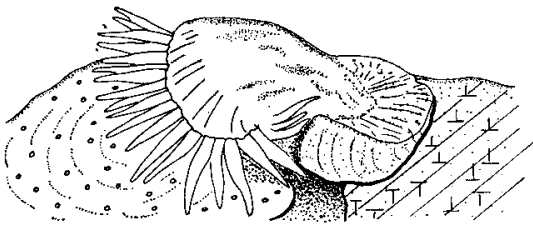

Fig. 4. A. Stomphia coccinea settled on stone (at right); tentacles in contact with shell (at left) without general clinging; pedal disk lifting and edge extending to make contact with shell; column short and unflexed.

B. S. coccinea transferring to shell; most tentacles extended and not clinging; pedal disk extremely convex, lifting and extending towards shell and never free of substratum; column constricted and flexed at base. ( $0.5 \mathrm{~min}$. between A \& B; Friday Harbor, U.S.A.).

N.B. Scale on Figs. 1, 2, 3 and 4 in cm. Figs. 2, 3 and 4 drawn from single frames on 16 mm. films.

\section{2) Quick Detachment and Swimming}

The second example of a special actinian behavior pattern is seen in the two kinds of swimming in which anemones engage. In one type, quick synchronised lashing movements of the tentacles propel the detached anemone through the water. This kind of swimming is seen in Boloceroides mcmurrichi (JOSEPHSON and MARCH, 1963) and in Gonactinia prolifera (RoBson, 1972). In the second mode of swimming seen in the actinostolids, Stomphia coccinea and Actinostola new spp., flexions of the lower column cause the animal to be propelled through the water or to creep about on the 
bottom. Film sequences which demonstrate the primary features of these two behavior patterns are available.

a) Boloceroides mcmurrichi. Swimming is triggered in this anemone by electrical stimuli and by mechanical stimuli such as tapping the wall of a glass tank. There are no preliminary movements. Quite suddenly the tentacles begin to pulsate and simultaneously the pedal disk detaches. The beat is perfectly synchronised, all tentacles lashing in unison. This behavior pattern as a whole has the appearance of a relatively simple rhythm produced by the excitation of a pacemaker system not unlike the beating of the bell of a medusa.

b) Actinostola new spp. Swimming in this animal is triggered by contact with two species of starfish, one nudibranch and by another swimming member of the Actinostolidae, Stomphia coccinea. It does not respond in this way to mechanical or tactile stimuli of any kind but a train of strong electrical stimuli can elicit this response. Swimming in this anemone seems to be a more complex behavior pattern than in Boloceroides or Gonactinia. Thus there are several preliminary movements before detachment and swimming begins. The swimming flexions are not synchronised around the column but localised in a single sector. They alternate from side to side and follow a spiral course (RoBson, 1961). The process of detachment seems to involve both the dissolution of the anchoring substances and also the formation of radiating folds on the pedal disc by the contraction of certain muscles at the base of the mesenteries (ELLIS, Ross and SutTon, 1969).

These are behavior patterns in which the goal is very obvious, viz., the removal of the anemone from the place to which it was attached. It is less obvious what the animal may achieve by carrying out this behavior pattern. If they are escape reactions, it is strange that the animals which elicit the reaction are not very obvious predators of the "escapees".

It has not yet been possible to identify or locate the swimming system which is triggered by the various stimuli named above. Wherever it is, this system is apparently independently excitable. It is at least functionally distinct from the general nerve net because when activated some other activities (retraction, feeding, etc.) are switched off.

\section{3) Relaxation and Inhibition}

The third example of a special behavior pattern in anemones is found also in the symbiotic species, Calliactis and its allies. This is the state of relaxation and inhibition produced by weak repetitive tactile stimuli which in nature are employed by crabs in picking up anemones to place them on their shells. Amongst the experimental methods used to obtain the same effect, gentle tactile stimulation as administered by a small brush or low frequency electrical stimulation are remarkably effective as can be shown by reference to the film sequences available (Ross and SUTTON, 1970).

This behavior pattern is not triggered like swimming but it occurs in three distinct stages, during which the stimuli must be applied continuously in order to complete 
the pattern. The first stage is to open up the anemone which usually closes down when the stimuli are first applied. The second stage is to produce in the anemone a state of complete relaxation in which the muscular tone virtually disappears. The third and final stage is the weakening of the attachment of the pedal disc leading to its eventual complete release.

How does the animal organise a behavior pattern of this kind? The behavior suggests that the machinery exists for feeding inhibitory impulses or transmitters into the main motor pathways which initiate and control most of the animal's activities. But it would be wrong to regard this behavior pattern as a simple case of general inhibition. It has an active side as well because the detachment almost certainly involves the dissolution of cementing substances which normally anchor the pedal disk to the substratum. Other superficial observations suggest that the same weak and low frequency stimuli that bring about the general relaxation and inhibition also cause mucus to be secreted all over the integument. I have almost always noted that when stroking is beginning to bring about relaxation, the column (which up to that time was rough and resisted the movement of any object across the surface) becomes smooth, soft and slippery. In other words, something much more than a general inhibitory response is involved in this behavior pattern. Some other motor pathways in the nerve net leading to glandular effectors are opened up for the conduction of excitation.

\section{Discussion and Conclusions}

One noteworthy feature about these special actinian behavior patterns which have definite and often precise goals is that they seem not to involve special effectors or receptors. Components of the normal musculature or of the glandular epithelium apparently can be called into play as required to produce the special movements that one sees in these behavior patterns. Thus the muscles used for swimming in the actinostolids are the parieto-basilars and they are only slightly better developed in Stomphia than in other anemones which do not swim in this way. The effector machinery seems to be available in the anemone to do almost anything within reasonable limits.

There is also no evidence of special receptors acting as triggers to initiate these various behavior patterns. The capacity to carry out these special behavior patterns seems instead to be based upon the adaptation of the general system of single-celled chemoreceptors to respond to definite modalities. Thus the swimming actinostolids must possess receptor cells in particular places which are sensitive to specific substances and which are able to act as triggers for swimming by virtue of their connections with the rest of the neuromuscular system. In the same way, anemones that live with hermit crabs presumably possess mechanoreceptors that respond to weak or low frequency stimulation by setting up excitation in the nervous system that leads to relaxation and to inhibitory effects generally in the muscular system. These receptors, 
which act as specific triggers, probably do not differ in principle from the normal chemoreceptors and mechanoreceptors common to all actinians. In other words, the material basis for the behavior patterns in these anemones is to be found neither in the effectors nor in the receptors. It must then be in the nervous system which, on receiving the appropriate information, achieves the goals of the behavior pattern by sending the appropriate signals to certain effectors.

The model of the actinian nervous system that is beginning to emerge in my mind is that it is a dispersed system differentiated into a considerable number of functional units and subunits. In thinking along these lines I am drawing from my own experiences as well as those of other workers in the field, especially Drs. RoBSON and MACFARLANE (whose inability to present his paper on "Multiple Conduction Systems" to this Symposium is a great disappointment). I am also much influenced by the work of my student, Daniel PETEYA, who has studied the nervous system of Cerianthiopsis with the electron microscope and has found there (from dimensions of fibres and granulation of synapses) evidence for four structural components in the nerve net (PETEYA, 1973). He is now extending this kind of study to Stomphia coccinea and the expectations are that several units may be identifiable here by the same methods. Thus we are not only moving beyond PANTIN's idea that the nerve net in actinians is a single excitable system but beyond the later notion that it consists of quick and slow components analogous to the giant and ordinary fibre systems of many other invertebrates. These conceptions did not adequately account for the routing of sensory information into definite motor channels, and especially in recruitment of quick and slow activities in special sequences as in the more complex behavior patterns discussed above. Questions about the control and coordination of the sequential activities in these behavior patterns were hardly touched upon.

As I see it, we are being driven towards the idea that the actinians possess the equivalent of a central nervous system in a dispersed form. Without some such arrangement it would be impossible to coordinate and to control the various activities and behavior patterns that these animals can carry out. Until more is known about the architecture of the actinian nervous system we can only guess how it is organised from the activities it performs.

At the moment I see no alternative but to suggest that actinians possess semiindependent networks for each of the main behavior patterns that they display. This would mean that those anemones that respond to shells possess a semi-independent motor system leading to all the muscles and glands that are used in this shell response. This subnetwork brings these effectors into action in the appropriate sequences as further information is fed back into the system. Given that such a system can be independently excited and kept excited until the behavior pattern reaches its goal, the requirements of the system are fairly obvious. Many of the same effectors used in the shell response are used for other purposes at other times but such activities would be generated by excitation in another network. 
I would postulate further that another independent motor system would be required to coordinate the interplay of inhibitory and excitatory events in the effectors during the detachment of a Calliactis by a crab. Similarly, swimming in the actinostolids and in some other anemones might also be controlled by an independent network capable of being excited by specific stimuli. This would leave the more basic activities of the animals, their reflex responses, their spontaneous activities, as the primary responsibilities of the general nerve net with its slower and faster conducting pathways as described by Pantin (1952).

This notion of the central functions of the nervous system being dispersed in independent networks reminds one that the assembling of nervous tissue in central aggregations is largely a consequence of the evolution of multicellular organs of special sense. Thus, generally, the evolution of complex behavior and discrimination has been accompanied by the evolution of aggregations of nerve tissue, which even in the Hydromedusae can be said to perform the functions of a central nervous system (MACKIE, 1970). Actinians may be unique in showing a line of behavioral evolution in which some highly complex motor activities have been developed using relatively simple information services composed of unicellular receptors. Ascertaining how the information from these receptors is fed into the appropriate channels to excite networks of neurones working in concert is a problem that will tax to the utmost the combined skills of the neurophysiologist and the neurohistologist.

\section{REFERENCES}

Batham, E. J. and Pantin, C. F. A. 1950. Inherent activity in the sea-anemone, Metridium senile (L.) J. Exp. Biol. 27, 290-301.

Carlgren, O. 1949. A Survey of the Ptychodactiaria, Corallimorpharia and Actiniaria. Kungl. Svensk. VetenskAkad. Handl. 1 (Ser. 4), 121 pp.

Ellis, V. L., Ross, D. M. and Sutton, L. 1969. The pedal disc of the swimming sea anemone Stomphia coccinea during detachment, swimming and resettlement. Can. J. Zool. 47, 333-342.

Josephson, R. K. and MARCH, S. C. 1966 . The swimming performance of the sea-anemone Boloceroides. J. Exp. Biol. 44, 493-506.

MACKIE, G. O. 1971. Neurological complexity in medusae: a report of central nervous organization in Sarsia. Actas del I simposio internacional de zoofilogenia. pp. 269-280. University of Salamanca.

Mackie, G. O. and Passano, L. 1968. Epithelial conduction in Hydromedusae. J. Gen. Physiol. 52, $600-621$.

MCFarlane, I. D. 1969 . Co-ordination of pedal-disk detachment in the sea anemone Calliactis parasitica. J. Exp. Biol. 51, 387-396.

Pantin, C. F. A. 1952. Croonian Lecture. The elementary nervous system. Proc. Roy. Soc. Lond. B, 140, 147-168.

Parker, G. H. 1919. The elementary nervous system. Lippincott. Philadelphia. p. 1-299.

PeteyA, D. J. 1973. A light and electron microscope study of the nervous system of Ceriantheopsis americanus (Cnidaria. Ceriantharia). Z. Zellforsch. 141, 301-317.

Ropson, E. A. 1961. Some observations on the swimming behaviour of the anemone Stomphia coccinea. J. Exp. Biol. 38, 343-363. 
RoBson, E.A. 1971. The behaviour and neuromuscular system of Gonactinia prolifera, a swimming sea-anemone. J. Exp. Biol. 55, 611-640.

Ross, D. M. and Sutton, L. 1961. The response of the sea anemone Calliactis parasitica to the shell of the hermit crab Pagurus bernhardus. Proc. Roy. Soc. Lond. B, 155, 266-281.

Ross, D. M. and Sutton, L. 1967. The response to molluscan shells of the swimming sea anemones Stomphia coccinea and Actinostola new species. Can. J. Zool. 45, 895-906.

Ross, D. M. and Sutron, L. 1970. The detachment of the commensal sea anemones, Calliactis polypus and C. tricolor by mechanical and electrical stimulation. Z. vergl. Physiol. 67, 102-119.

\section{DISCUSSION}

G. O. MACKIE: Is it necessary to suppose that different behaviour patterns are organised by different components of the nerve net? Could one not obtain different activities from one net by use of frequency-coded signals generated by specific net pacemakers?

Ross: I agree that one should not postulate separate components of the nerve net if one net will do the job. But I am not postulating components that are completely independent. The special behaviour patterns can sometimes be interrupted by other events (e.g. retraction) and they can only proceed if some other activities are inhibited. Therefore contact must exist with the rest of the nervous system. My point is that the special behaviour patterns can be explained on the basis of special lines of communication without the involvement of the entire nerve net.

As evidence of the notion of semi-independent units, I refer again to MACFARLANE whose work has led him to the conclusion that the nerve net consists of multiple conducting units. His SS1 activity is located in the ectoderm and is specifically associated with the shell response whereas other electrical activities are located in the endoderm and they are associated with other behavioural events.

As a general argument for the notion of semi-independent functional components of the nerve net, I would cite the adaptability and uniqueness of some special behaviour patterns. Their responsiveness to the specific demands of the circumstances suggest something more complicated and adaptable than frequency-coded pacemaker signals which I would expect to be more stereotyped and also to make many more mistakes than actually occur.

You may be right in your notion that specific pacemakers giving off signals of specific frequencies could explain these activities. What concerns me is the route or routes by which the message travels from the pacemakers (or the controlling neurones) to the effectors. We have generally avoided ideas of sensory, central and motor components in the actinian nerve net and this may be the source of some of our conceptual difficulties. The experiences of Romanes and later of PARKER and PANTIN showed the nerve net conducting excitation symmetrically throughout the entire animal. This suggested that the network is excited as a whole or not at all and that it is completely undifferentiated. In some activities such as retraction in anemones and the pulsation of medusae, the general nerve net acting as a single excitable system is involved. The special behaviour patterns can only be organised, in my opinion, outside this single excitable system by some quasi-central elements (your "pacemakers"). The peripheral pathways leading from these "central" elements bring the effectors into action in the correct sequences and can be regarded as functional units comparable to the motor units of more highly organised systems. I find it easier to think of them also as morphologically distinct rather than frequency-coded events in a general nerve net that are turned on in response to certain triggering stimuli. 